\title{
The Cardiovascular Risk Prediction of Epicardial Fat Thickness in Metabolic Syndrome Patients
}

\author{
Hanife Usta Atmaca, (1) Feray Akbaş \\ Department of Internal Medicine, Istanbul Training and Research Hospital, Istanbul, Turkey
}

\begin{abstract}
Introduction: Epicardial adipose tissue (EAT) is a visceral adipose tissue surrounding heart and coronary arteries. It is shown to be associated with increased cardiovascular disease risk and mortality. Here, we aimed to search for the relationship between Framingham-10-year-coronary heart disease risk and epicardial fat thickness (EFT) in metabolic syndrome (MetS) patients.

Methods: A total of 35 patients, 25 female and 10 male, with MetS were included in the study. Cardiac risk factors (age, gender, total cholesterol, high-density lipoprotein [HDL] cholesterol, smoking, systolic blood pressure [BP], and medication) determined by Framingham Heart Study were screened to use Framingham-10-year-coronary heart disease risk tool to assess the cardiovascular risk. EFT was measured with two-dimensional (2D) echocardiography. Results were evaluated using SPSS. Results: BP was normal in 62.9\%, in upper normal range in $28.6 \%$ and high in $8.6 \%$ of the patients. There was positive correlation between EAT and waist circumference (WC) and no correlation between age, fasting blood glucose (FBG), triglyceride (TG), HDL, total cholesterol, N/L ratio, Framingham risk score (FRS), and EAT. There was statistically significant difference in BP groups for TG, WC, and FRS but no difference for other parameters evaluated. Mean WC, N/L ratio, and FRS were statistically significant higher in men compared to women.

Discussion and Conclusion: Relation of EFT and MetS is shown in literature. Although EFT is not found to predict the cardiovascular risk in MetS in our study; smoking, HT and male gender are related to increased cardiovascular risk and this finding might help to determine the treatment priorities to prevent further cardiac damage in MetS patients.
\end{abstract}

Keywords: Epicardial fat thickness; Framingham risk score; metabolic syndrome.

Estons picardial adipose tissue (EAT) is a visceral adipose tissue - surrounding heart, especially epicardial vasculature. EAT is increased concomitant with visceral adipose tissue and it is accepted as visceral adipose tissue equivalent. It is an active organ that secrets several hormones, cytokines, and chemokines ${ }^{[1,2]}$ and with its increase, it produces pro-inflammatory and pro-atherogenic cytokines (e.g., Tumor necrosis factor (TNF), Interleukin 6 (IL-6), and Type 1 Plasminogen activator inhibitor). It is an energy source for myocardium and is protective against toxic effects of free fatty acids $[3,4]$.

Although it is not clear whether the increase in epicardial fat thickness (EFT) predisposes cardiovascular diseases or it is increased as a compensatory answer in cardiovascular disease, several studies showed the relationship of EFT and cardiovascular disease.

Metabolic syndrome (MetS) is the general name for a sequence of diseases consisting of obesity, elevated blood

Correspondence (iletişim): Hanife Usta Atmaca, M.D. Istanbul Egitim ve Arastirma Hastanesi, Istanbul, Turkey

Phone (Telefon): +90 2124596235 E-mail (E-posta): hanifeusta@yahoo.com

Submitted Date (Başvuru Tarihi): 24.05.2018 Accepted Date (Kabul Tarihi): 28.07.2018

Copyright 2019 Haydarpaşa Numune Medical Journal

This is an open access article under the CC BY-NC license (http://creativecommons.org/licenses/by-nc/4.0/). 
pressure (BP), impaired lipid, and glucose metabolism. It is related with increased cardiovascular morbidity and mortality ${ }^{[5]}$. By the increase in awareness of cardiovascular diseases, different modeling systems have been developed recently; these models help to predict cardiovascular event risks using different risk factors. One of the frequently used models is Framingham 10-year-cardiovascular disease risk calculator. Although the relationship between EFT and MetS and its components have been well described in studies, its importance about the long-term prediction of cardiovascular disease risk is still unclear.

In our study, we evaluated cardiovascular risk using Framingham 10-year-cardiovascular disease risk calculator and investigated the relationship between these risk factors and EFT and its prediction of future cardiovascular disease possibility.

\section{Materials and Methods}

A total of 35 patients, 25 female and 10 male, with MetS diagnosis were included in the study. Their medical histories, smoking habits, and clinical findings were recorded.

BP was measured after 10 min rest, at sitting position. The mean value of at least three measurements from different clinic visits was taken.

MetS diagnosis was made according to the International Diabetes Foundation - 2005 criteria:

- Abdominal obesity (WC: $94 \mathrm{~cm}$ in Caucasian men, $80 \mathrm{~cm}$ in Caucasian women).

- And at least 2 of the following criteria

- Triglyceride (TG) $150 \mathrm{mg} / \mathrm{dl}$.

- High-density lipoprotein (HDL)-chol: $<40 \mathrm{mg} / \mathrm{dl}$ in men, $<50 \mathrm{mg} / \mathrm{dl}$ in women.

- BP $130 / 85 \mathrm{mmHg}$.

- Glucose $100 \mathrm{mg} / \mathrm{dl}$ or Type 2 Diabetes mellitus (DM).

Cardiovascular risk was calculated using Framingham 10-year-cardiovascular disease risk calculator. Six risk factors were used for the calculation (gender, T-cholesterol, HDL-C, systolic or diastolic BP [under treatment or not], and smoking) and the 10-year risk was calculated as a percentage ${ }^{[6]}$. EAT was measured by transthoracic 2D-echocardiography. Results were evaluated using SPSS.

Waist circumference (WC): Minimum WC (in $\mathrm{cm}$ ) (minimum circumference between the lower rib margin and the iliac crest, mid waist) and maximum hip circumference (in centimeters) (the widest diameter over the greater trochanters) were measured while the subjects were standing with their heels together.

\section{Laboratory Measurements}

Fasting blood samples were obtained, and plasma glucose, uric acid, TG, total cholesterol, HDL cholesterol, low-density lipoprotein (LDL) cholesterol, and C-reactive protein (CRP) levels were measured. LDL cholesterol was evaluated with directly homogenous enzymatic calorimetric method (Roche Diagnostics, GMbH, Mannheim, Germany) using PP modular kits and CRP measured by the immunoturbidimetric method (Roche Diagnostics, GMbH, Mannheim, Germany).

\section{Statistical Analysis}

Statistical analysis was performed using SPSS 15.0 for Windows program. Descriptive statistics were reported as number and percentage for categorical variables and as mean and standard deviation for numerical variables. When the numerical variables were distributing normally, in comparison of $>2$ independent groups one-way analysis of variance, if those groups were not distributing normally, Kruskal-Wallis tests were performed. In non-parametric tests, subgroup analysis was performed with the MannWhitney U-test and commented with Bonferroni correction. The ratios of categorical variables between groups were tested with Chi-square test. When parametric test criteria could not be achieved, the associations of numerical variables were investigated with Spearman correlation analysis. The discriminating factors were tested with linear regression analysis. The statistical alpha significance level was regarded as $\mathrm{p}<0.05$.

Informed consent was obtained from all patients, and the study was approved by our Local Ethical Committee (Istanbul Training and Research Hospital Ethical Committee).

\section{Results}

A total of 35 patients, 25 female and 10 male, with MetS diagnosis were included in the study. Their mean age was $52.29 \pm 10.21$ years, and the smoking rate was $31.4 \%$. Their BP was found to be: $62.9 \%$ normal, $28.6 \%$ upper normal, and $8.6 \%$ high. The demographic, clinical and biochemical characteristics of patients are summarized in Table 1.

The smoking rate of men was statistically significant higher than women $(<0.001)$. There was no statistically significant difference between two gender groups for BP $(p=0.254)$. The mean value of $\mathrm{HDL}-\mathrm{C}$ was statistically significant higher in women when compared to men $(p=0.001)$.WC and mean cardiac risk score (CRS) was statistically significant higher in men than women $(p=0.008, p=0.029, p=0.039, p=0.029$ in order). There was no statistically significant difference between two gender groups for mean values of age, fasting 
blood glucose (FBG), uric acid, total reflection grating, $\mathrm{LDL}$, T. cholesterol, insulin, EFT, and $N / L$ ratio $(p=0.117, p=0.283$, $p=0.343, p=0.268, p=0.119, p=0.406, p=0.162, p=0.408$ ， $\mathrm{p}=0.693$ in order). The relationship between EFT and other variables is shown in Table 1.

There was statistically significant difference in BP groups for mean TG, WC, and CRS values ( $p=0.024, p=0.024, p=0.015$ in order). There was no statistically significant difference between other variables.

In a single variable analysis made to determine the factors that effect EFT, among factors with $\mathrm{p}<0.05$ in the model created with age, gender, and mean CRS, the most important factors effecting EFT were found to be WC and LDL-C $(p=0.020, p=0.036)$ Table 2 .

\section{Discussion}

In this study, where we investigated the relationship between EFT and Mets components and its possible use for long-term prediction of cardiovascular disease risk; we found a close relationship between EFT and HT and WC, but it was insufficient to predict the future cardiovascular risk alone.

EFT plays an active role in coronary artery disease origination ${ }^{[7]}$. Increase in EFT leads to endocrine and paracrine effects that cause cardiovascular structural changes and added to low-grade inflammation seen in Mets; it increases cardiovascular disease risk. In literature, the relationship of increased EFT and cardiovascular diseases such as impaired microvascular coronary flow [8], atrial fibrillation [9], prolonged QT time ${ }^{[10]}$, left ventricular diastolic disfunction [11], sublinical atherosclerosis ${ }^{[12]}$, and increased coronary atherosclerotic load ${ }^{[13]}$ is shown.

In previous studies, a relationship between EFT and Mets components is shown. In a meta-analysis made by Rabkin et al. [14]; EFT was increased significantly in the metabolic syndrome group and was correlated with TG, WC, and systolic BP. Yorgun et al. ${ }^{[15]}$ also found a significant correlation between EAT and MetS components.

WC is the major criteria of MetS and used widely to assess visceral adiposity. It is found to be a stronger cardiovascular risk predictor than body mass index (BMI) ${ }^{[16]}$. Our study similarly showed a strong correlation between EAT and WC. In hypertensive patient group, WC was found significantly higher than the normotensive group, and that contributed to the increased cardiovascular risk score.

Impaired glucose tolerance and diabetes mellitus are a part of MetS and show a close relationship with EFT. Lacobellis et al. ${ }^{[17]}$ showed a significant correlation between EFT and MetS components (insulin sensitivity, glucose intolerance,
Table 2. The relationship between EFT and biochemical parameters

\begin{tabular}{lcc}
\hline & \multicolumn{2}{c}{ EFT } \\
\cline { 2 - 3 } & Rho & P \\
\hline Age & -0.031 & 0.874 \\
WC & 0.396 & 0.034 \\
FBG & 0.057 & 0.768 \\
Uric Acid & -0.148 & 0.443 \\
TRG & 0.276 & 0.147 \\
LDL & -.0400 & 0.035 \\
HDL & -0.323 & 0.088 \\
T. cholesterol & -0.242 & 0.206 \\
Insulin & -0.047 & 0.862 \\
Neutrophil & 0.112 & 0.563 \\
Lymphocyte & 0.200 & 0.299 \\
N/L & -0.002 & 0.992 \\
CRS\% & -0.001 & 0.995
\end{tabular}

CRS: Cardiac risk score; WC: Waist circumference; LDL: Low-density lipoprotein; HDL: High-density lipoprotein; TRG: Total reflection grating; FBG: Fasting blood glucose.

Table 1. Demographic, clinical and biochemical characteristics of subjects

Age (year)

$52.29 \pm 10.21 / 54$

Gender n (\%)

Female

$25(71.4)$

Male

$10(28.6)$

Smoking $\mathrm{n}(\%)$

$(+)$

$11(31.4)$

$(-)$

24 (68.6)

BP n (\%)

Normal

$22(62.9)$

Upper Normal

$10(28.6)$

High

$3(8.6)$

$\mathrm{FBG}$ mean $\pm \mathrm{SD} /$ median

$118.71 \pm 58.08 / 103$

Uric acid mean $\pm \mathrm{SD} /$ median

$5.64 \pm 1.35 / 5.4$

TG mean \pm SD/median

$221.06 \pm 158.54 / 183$

$\mathrm{LDL}(\mathrm{mg} / \mathrm{dl})$ mean $\pm \mathrm{SD} /$ median

$133.37 \pm 44.67 / 135$

$\mathrm{HDL}(\mathrm{mg} / \mathrm{dl})$ mean $\pm \mathrm{SD} /$ median

$44.54 \pm 11.13 / 43$

T. cholesterol (mg/dl) mean $\pm \mathrm{SD} /$ median

$221.11 \pm 47.88 / 223$

WC Mean $\pm S D /$ median

$99.60 \pm 9.51 / 98$

Insulin mean $\pm \mathrm{SD} /$ median

$14.51 \pm 15.36 / 10.78$

Neutrophil mean $\pm \mathrm{SD} /$ median

$4561.14 \pm 1208.31 / 4470$

Lymphocyte mean $\pm \mathrm{SD} /$ median

$2295.43 \pm 595.70 / 2080$

Neutrophil/Lymphocyte

$2.08 \pm 0.71 / 1.99$

mean $\pm \mathrm{SD} /$ median

EFT percentage $(\mathrm{mm})$

$0.49 \pm 0.16 / 0.47$

CRS mean \pm SD/median

$6.80+9.23 / 2$

CRS: Cardiac risk score; SD: Standard deviation; EFT: Epicardial fat thickness; TG: Triglyceride; FBG: Fasting blood glucose; WC: Waist circumference; LDL: Low-density lipoprotein; HDL: High-density lipoprotein; BP: Blood pressure. 
LDL-C, and BP). Chun et al. found a correlation between increased DM prevalence and EFT in their study.

This correlation is thought to be caused by increased secretion of some cytokines. Increase in cytokines (e.g., TNF-alpha, IL-1, IL-6, Free fatty acids (FFA), plasminogen activator inhibitor-1, and adiponectin) that are secreted from adipose tissue and related to inflammation, affect the development of DM, obesity, and dyslipidemia ${ }^{[18]}$. These cytokines might also cause accelerated atherosclerosis, plaque instability, and arterial thrombosis. GLUT-4 protein that is involved in glucose uptake through insulin, is shown to be decreased in both epicardial and visceral adipose tissue in diabetic patients [19]. In our study, EFT is found to be directly related to the FBG level. This might be due to diabetes age, the medication that has been received or accompanying diseases.

Hypertension is an important risk factor for coronary artery disease and atherosclerosis and is also a component of MetS. The hemodynamic load and increase in pressure in hypertension, cause myocyte hyperplasia and capillary proliferation leading to an increase in ventricular wall thickness. As a result, myocardium's energy need is enhanced, and the increase in EFT is thought to be a maladaptive process that happens to provide myocardium's energy need through FFA. There are several studies supporting the increase in EFT in $\mathrm{HT}{ }^{[20]}$. It is also shown that EFT is increased even in prehypertensive patients when compared to normal people [21]. Although EFT is increased in hypertensive patient group in our study when compared to the normotensive group, it is not statistically significant. This might be due to a small number of patients, multidrug use, few number of Grade 2-3 hypertensive patients, common use of angiotensin-converting enzyme inhibitors and angiotensin receptor blocker which decrease cardiac remodeling and has anti-inflammatory and anti-proliferative effects $[22,23]$. The presence of hypertrygliseridemic waist in the hypertensive group also supports the EFT increase. Although EFT is shown to be related to cardiovascular disease risk ${ }^{[13]}$, we did not get the same result for long-term cardiac risk calculation using Framingham risk score calculator. This might be caused by the presence of several risk factors that can be modified. There is no other study in literature explaining such results. Only Nelson et al. showed a weak relationship in a similar study ${ }^{[24]}$. In our study, we found increased cardiac risk in hypertensive patients and male patients.

Magnetic resonance imaging (MRI) is the golden standard for EAT measurement, but echocardiography is a non-inva- sive and cheap method for EAT measurement. lobellis et al. ${ }^{[7]}$ showed results with similar sensitivity for EAT measurement with $\mathrm{ECHO}$ when compared to MRI and with $\mathrm{CT}$ in another study ${ }^{[25]}$.

The cutoff value of EFT is not clear and is different in studies. In MetS, lobellis et al. ${ }^{[26]}$ declared it as $9.5 \mathrm{~mm}$ in male and $7.5 \mathrm{~mm}$ in female, Natale et al. as $7 \mathrm{~mm}$ both in male and female in subclinical atherosclerosis, and Eroğlu et al. [27] as 5.2 for coronary artery disease. Pierdominica et al. ${ }^{[28]}$ found it as 2.5 and $7.1 \mathrm{~mm}$ in normal population, Faghihi et al. ${ }^{[29]} 2.95 \mathrm{~mm}$ for early atherosclerosis. We found mean EAT as $4.7 \mathrm{~mm}$ in females and $5.3 \mathrm{~mm}$ in males in MetS. It was $4.8 \mathrm{~mm}$ in normotensive while $5.3 \mathrm{~mm}$ in hypertensive patients, the difference was not statistically significant.

\section{Conclusions}

We showed that the most important factor that predicted EAT is visceral adiposity and as its reflection, WC but it was not a tool to predict the cardiovascular disease risk alone. Moreover, hypertension is an important risk factor for long-term cardiovascular risk scoring, independent of MetS and EFT.

\section{Limitations of Our Study}

Studies with a greater number of subjects who would be followed for a longer term could be more beneficial. The effect of weight loss and treatment on EFT should be investigated. Number of patients, short follow-up time and being cross-sectional are limiting our study. Left ventricular mass index and BMI and their relationship with EFT would add to the significance of the study.

\section{Acknowledgments}

We would like to thank cardiologist Dr. Huseyin Karakurt for his contribution to our study about data collection.

Ethics Committee Approval: Informed consent was obtained from all patients, and the study was approved by our Local Ethical Committee (Istanbul Training and Research Hospital Ethical Committee).

Peer-review: Externally peer-reviewed.

Authorship Contributions: Concept: H.U.A.; Design: H.U.A.; Data Collection or Processing: H.U.A., F.A.; Analysis or Interpretation: H.U.A., F.A.; Literature Search: H.U.A., F.A.; Writing: H.U.A.

Conflict of Interest: None declared.

Financial Disclosure: The authors declared that this study received no financial support. 


\section{References}

1. Sacks HS, Fain JN. Human epicardial adipose tissue: a review. Am Heart J 2007;153:907-17. [CrossRef]

2. Rabkin SW. Epicardial fat: properties, function and relationship to obesity. Obes Rev 2007;8:253-61. [CrossRef]

3. lacobellis $\mathrm{G}$, Barbaro $\mathrm{G}$. The double role of epicardial adipose tissue as pro-and antiinflammatory organ. Horm Metab Res 2008;40:442-5. [CrossRef]

4. Baker AR, Silva NF, Quinn DW, Harte AL, Pagano D, Bonser RS, et al. Human epicardial adipose tissue expresses a pathogenic profile of adipocytokines in patients with cardiovascular disease. Cardiovasc Diabetol 2006;5:1. [CrossRef]

5. Grundy SM, Brewer HB Jr, Cleeman Jl, Smith SC Jr, Lenfant C; American Heart Association; National Heart, Lung, and Blood Institute. Definition of metabolic syndrome: Report of the National Heart, Lung, and Blood Institute/American Heart Association conference on scientific issuesrelated to definition. Circulation 2004;109:433-8. [CrossRef]

6. Lloyd-Jones DM, Larson MG, Beiser A, Levy D. Lifetime risk of developing coronary heart disease. Lancet 1999;353:89-92.

7. lacobellis G, Assael F, Ribaudo MC, Zappaterreno A, Alessi G, Di Mario U, et al. Epicardial fat from echocardiography: a new method for visceral adipose tissue prediction. Obes Res 2003;11:304-10. [CrossRef]

8. de Vos AM, Prokop M, Roos CJ, Meijs MF, van der Schouw YT, Rutten A, et al. Peri-coronary epicardial adipose tissue is related to cardiovascular risk factors and coronary artery calcification in post-menopausal women. Eur Heart J 2008;29:777-83. [CrossRef]

9. Chao TF, Hung CL, Tsao HM, Lin YJ, Yun CH, Lai YH, et al. Epicardial adipose tissue thickness and ablation outcome of atrial fibrillation. PLoS One 2013;8:e74926. [CrossRef]

10. Kaplan O, Kurtoglu E, Nar G, Yasar E, Gozubuyuk G, Dogan C, et al. Evaluation of Electrocardiographic T-peak to T-end Interval in Subjects with Increased Epicardial Fat Tissue Thickness. [Article in English, Portuguese]. Arq Bras Cardiol 2015;105:566-72.

11. Cavalcante JL, Tamarappoo BK, Hachamovitch R, Kwon DH, Alraies MC, Halliburton $S$, et al. Association of epicardial fat, hypertension, subclinical coronary artery disease, and metabolic syndrome with left ventricular diastolic dysfunction. Am J Cardiol 2012;110:1793-8. [CrossRef]

12. lacobellis G, Pellicelli AM, Sharma AM, Grisorio B, Barbarini G, Barbaro $G$. Relation of subepicardial adipose tissue to carotid intima-media thickness in patients with human immunodeficiency virus. Am J Cardiol 2007;99:1470-2. [CrossRef]

13. Bettencourt N, Toschke AM, Leite D, Rocha J, Carvalho M, Sampaio $F$, et al. Epicardial adipose tissue is an independent predictor of coronary atherosclerotic burden. Int J Cardiol 2012;158:26-32. [CrossRef]

14. Rabkin SW. The relationship between epicardial fat and indices of obesity and the metabolic syndrome:a systematic review and meta-analysis. Metab Syndr Relat Disord 2014;12:31-42.

15. Yorgun H, Canpolat U, Hazirolan T, Ateş AH, Sunman H, Dural $M$, et al. Increased epicardial fat tissue is a marker of metabolic syndrome in adult patients. Int J Cardiol 2013;165:308-13.

16. Rimm EB, Stampfer MJ, Giovannucci E, Ascherio A, Spiegelman
D, Colditz GA, et al. Body size and fat distribution as predictors of coronary heart disease among middle-aged and older US men. Am J Epidemiol 1995;141:1117-27. [CrossRef]

17. lacobellis G, Ribaudo MC, Assael F, Vecci E, Tiberti C, Zappaterreno $A$, et al. Echocardiographic epicardial adipose tissue is related to anthropometric and clinical parameters of metabolic syndrome: a new indicator of cardiovascular risk. J Clin Endocrinol Metab 2003;88:5163-8. [CrossRef]

18. lacobellis G, Pistilli D, Gucciardo M, Leonetti F, Miraldi F, Brancaccio $G$, et al. Adiponectin expression in human epicardial adipose tissue in vivo is lower in patients with coronary artery disease. Cytokine 2005;29:251-5. [CrossRef]

19. Salgado-Somoza A, Teijeira-Fernández E, Rubio J, Couso E, González-Juanatey JR, Eiras S. Coronary artery disease is associated with higher epicardial retinolbinding protein 4 (RBP4) and lower glucose transporter (GLUT) 4 levels in epicardial and subcutaneous adipose tissue. Clin Endocrinol (Oxf) 2012;76:51-8.

20. Sironi AM, Pingitore A, Ghione S, De Marchi D, Scattini B, Positano $\mathrm{V}$, et al. Early hypertension is associated with reduced regional cardiac function, insulin resistance, epicardial, and visceral fat. Hypertension 2008;51:282-8. [CrossRef]

21. Turak O, Özcan F, Canpolat U, Mendi MA, Öksüz F, Özeke Ö, et al. Relation between epicardial adipose tissue thickness and blood pressure levels in prehypertension. Turk Kardiyol Dern Ars 2014;42:358-64. [CrossRef]

22. Pfeffer MA, Pfeffer JM, Braunvald E. Influence of choronic captopril therapy on the infarcted left ventricle of the rat. Circ Res 1985;57:84-95. [CrossRef]

23. Pfeffer MA, Pfeffer JM, Steinberg C, Finn P. Survival after an experimental myocardial infaction: benefical effects of longterm therapy with captopril. Circulation 1985;72:406-12.

24. Nelson MR, Mookadam F, Thota V, Emani U, Al Harthi M, Lester SJ, et al. Epicardial fat: an additional measurement for subclinical atherosclerosis and cardiovascular risk stratification? J Am Soc Echocardiogr 2011;24:339-45. [CrossRef]

25. Lai YH, Yun CH, Yang FS, Liu CC, Wu YJ, Kuo JY, et al. Epicardial adipose tissue relating to anthropometrics, metabolic derangements and fatty liver disease independently contributes to serum high-sensitivity C-reactive protein beyond body fat composition: a study validated with computed tomography. J Am Soc Echocardiogr 2012;25:234-41. [CrossRef]

26. lacobellis G, Willens HJ, Barbaro G, Sharma AM. Threshold values of high risk echocardiographic epicardial fat thickness. Obesity (Silver Spring) 2008;16:887-92. [CrossRef]

27. Eroglu S, Sade LE, Yildirir A, Bal U, Ozbicer S, Ozgul AS, et al. Epicardial adipose tissue thickness by echocardiography is a marker for the presence and severity of coronary artery disease. Nutr Metab Cardiovasc Dis 2009;19:211-7. [CrossRef]

28. Pierdomenico SD, Pierdomenico AM, Cuccurullo F, lacobellis G. Meta-analysis of the relation of echocardiographic epicardial adipose tissue thickness and the metabolic syndrome. Am J Cardiol 2013;111:73-8. [CrossRef]

29. Faghihi S, Vasheghani-Farahani A, Parsaee M, Saedi S, Ghadrdoost B. Association between epikardial fat thicness and prematüre coronary artery disease: A case Control Study. Res Cardiovasc Med 2015;23:4:e25679. 